\title{
O ruim e as ruínas Sobre Punctum, de Martín Gambarotta
}

Mario Cámara

Universidad de Buenos Aires

Sombra terrivel de Facundo, vou invocar-te, para que, sacudindo o ensanguentado pó que cobre tuas cinzas, levanta-te para nos explicar a vida secreta e as convulsões internas que desgarram as entranhas de um nobre povo.

Domingo Faustino Sarmiento

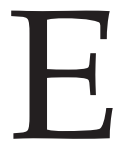

m 1995, o livro de poemas do jovem Martín Gambarotta, Punctum obteve o primeiro prêmio do Diário de Poesia e deu início a uma imediata controvérsia em torno de sua valorização. Apesar das polêmicas iniciais, o prêmio recebido representava a consolidação e a renovação de um movimento poético, o objetivismo, que tinha começado a se tornar visível na Argentina desde a segunda metade dos anos oitenta como resposta ao que Edgardo Dobry chama "os últimos suspiros da vanguarda no Río de la Plata", referindo-se com isso ao neobarroco. O ponto de partida para o objetivismo tinha sido o texto de Daniel García Helder, "O neobarroco na Argentina", publicado em 1987 no quarto número do Diário de Poesia, que propunha opor ao léxico luxuoso do neobarroco, e a indeterminação do sentido um máximo de sentido. $\mathrm{O}$ objetivismo devia ser uma poesia "arraigada em sua tarefa de 
conseguir algum tipo de beleza mediante a precisão, o breve, a fácil ou difícil clareza"1.

Todavia, entre os inícios do objetivismo, ou seja, entre Daniel García Helder, Rafael Bielsa, Daniel Freidemberg e Jorge Fondebrider, e Martín Gambarotta, e alguns dos que podem se considerados seus companheiros de geração, como Juan Desiderio ou Alejandro Rubio, para citar apenas dois, se produziram notáveis diferenças. Se em seu escrito fundamental, García Helder apelava a Pound para propor uma linguagem carregada de sentido, nos mais jovens parecia haver uma recusa de tudo que "cheirasse" a literatura; se para os primeiros o neobarroco era o movimento a ser superado, para esta nova geração, o neobarroco não só tinha deixado de ser o outro bando, como simplesmente tinha deixado de ser.

Seria interessante recuperar a conferência que Martín Gambarotta profere em agosto de 2004 no Centro Cultural da Espanha, cujo título é "A fala como matéria prima", como um modo de entender o novo lugar que estes jovens - o próprio Gambarotta, Desiderio, Rubio - pretendiam escolher para si. Ao narrar suas origens como escritor, Gambarotta se refere à novela Glosa, de Juan José Saer - de quem, segundo suas palavras, já tinha lido e admirado El limonero real, Cicatrices, Nadie nada nunca e La mayor -, e o faz para afirmar que o personagem central, Ángel Leto,deixara-o "um tanto distante, um tanto ridículo e afetado" ${ }^{\prime 2}$, ao que acrescenta:

Às vezes a estrutura me parecia muito artificial. E o problema que eu também tinha, quando o lia, era que evidentemente esta era uma novela política, um tema que nesse momento me

${ }^{1}$ Apud PRIETO, 2006, p. 452.

${ }^{2}$ GAMBAROTTA, 2006, p. 238. 
interessava muito, e é a justificativa que encontro para o fato de me debruçar nessa discussão tão animada com este livro. ${ }^{3}$

Concluindo que "o 'fracasso' de Glosa me permitiu vislumbrar como leitor o que me parecia que era o ponto de uma nova literatura argentina"4. Recordemos que Glosa, publicada em 1985, narra uma caminhada compartilhada entre Angel Leto e o Matemático durante sessenta minutos e vinte e uma quadras em 1961, na qual o Matemático lhe conta a festa de aniversário de Washington Moriega, que por sua vez lhe tinha sido contada, dias antes, por Botón, a quem Leto não conhece pessoalmente. Nessa mesma caminhada, em um dado momento, juntam-se a eles Tomatis, que narrará sua própria versão do aniversário. Pouco antes do clímax da história ficamos sabendo do futuro militante de Ángel Leto, ou melhor, de seu fracasso ${ }^{5}$, e da morte auto infligida pela ingestão de uma cápsula de arsênico, obrigada por uma emboscada militar, durante a última ditadura.

Não seria simples detectar porque o personagem de Ángel Leto sonhado por Gambarotta é"distante", "ridículo" e "afetado", nem tampouco saber porque a estrutura lhe é apresentada como artificial. Talvez devamos buscar uma explicação no sistema de consagração crítica que ele estava

${ }^{3}$ GAMBAROTTA, 2006, p. 238.

${ }^{4}$ GAMBAROTTA, 2006, p. 238.

${ }^{5}$ Sobre sua militância, Leto pensa o seguinte: “Habiéndose dado cuenta al cabo de quince años que luchar a ciegas contra la opresión puede engendrar más opresión en lugar de acabar con ella, del mismo modo que ciertos métodos para combatir un incendio contribuyen más bien a acrecentar la fuerza de las llamas, y habiendo llegado demasiado lejos como para dar marcha atrás, empezará a confiar, no en estrategias, ni en organizaciones, ni en sacudimientos históricos, como los llaman, ni siquiera en su propia ametralladora, sino únicamente en la pastilla, en su pastilla, como quien podría decir, como se dice, en su sexto sentido o en su buena estrella" (SAER, 1995, pp. 270-271) 
construindo em torno da literatura de Saer. Neste sentido, os nomes de María Tereza Gramuglio e Beatriz Sarlo são indispensáveis. Muito precocemente - na revista Los libros de setembro de 1969 - María Tereza Gramuglio publica um texto sobre Cicatrizes de Saer, que tinha sido editado nesse mesmo ano; nele sustentava:

A técnica narrativa de Cicatrices [...] parece zombar dos recursos tradicionais: algo já tem sido dito, a propósito de Responso, sobre o classicismo narrativo de Saer. São os signos da novela, no sentido que Barthes nos assinala, no sentido de que alguns narradores contemporâneos se empenham justamente em denunciar e destruir, aqueles que Saer elege consciente e deliberadamente para construir Cicatrices. Nada mais distante de sua intenção que é propor a destruição e o aniquilamento desses signos. Pelo contrário, justamente a partir da reivindicação da escrita novelística, a partir de um obstinado começo em aderir a esses signos com uma fidelidade que chega à exasperação a partir, em suma, da crença no poder da palavra... ${ }^{6}$

Funda, deste modo, uma orientação na apreciação crítica que se sustentará com o tempo - que destaca o poder da palavra e a excelência formal. Alguns anos mais tarde somará, desde as páginas da revista Punto de Vista, o ensaio intitulado "Juan José Saer: a arte de narrar", em que afirma: "A memória, ou melhor, a recordação, e o que a alimenta, o tempo: a percepção sensorial e as falácias da representação; a cegueira (a ilusão da totalidade) e o ver (os fragmentos, as manchas): passos de uma escrita que desdobra a história de sua opressão, de sua incomodidade, e que se nega a propor na narração [...] nenhum triunfo, nenhum reino, para além de si mesma"7. Às falácias da representação,

${ }^{6}$ GRAMUGLIO, 1969.

${ }^{7}$ GRAMUGLIO, 1977, p. 8. Referindo-se a El entenado, Gramuglio 
Gramuglio opõe um triunfo da escrita. Entretanto, Beatriz Sarlo define a produção de Saer como "uma obra que nunca desmentiu sua radicalidade estética e cuja perfeição se funda na coerência da experimentação narrativa" ${ }^{\prime \prime}$. As citações, que funcionam apenas como exemplo e poderiam se multiplicar, permitem entrever que a afetação, o ridículo e a distância que diagnostica Gambarotta podem ser atribuídas às qualidades de Saer, como se no lugar de ver ali uma escrita de qualidade indiscutível, observasse um tipo de "excesso de literatura".

Aceitemos por um momento essa hipótese, pois ela nos permitirá assinalar que esse "excesso de literatura" não conduz Gambarotta a uma escrita realista, ou descuidada, mas (pelo contrário), e aqui me adianto à linha de minha argumentação, ao "fracasso" de um poeta como Juan Desiderio e a sua "valetinha". Com efeito, como contraposição a Glosa, Gambarotta, na conferência mencionada, se refere ao livro de poemas La zanjita, de Juan Desiderio:

Es un texto jugado al fracaso, al punto que las " $y$ " suplantan a las "ll". A mí me pareció magistral la lectura de Desiderio, como si estuviera viendo a Hendrix en 1967, antes de que lo hubieran descubierto otros. ${ }^{9}$

A simpatia pelo fracasso, creio, reafirma a hipótese proposta no parágrafo anterior. O nome do músico Jimi Hendrix ${ }^{10}$, e considerando que Gambarotta menciona a leitura

reafirma o poder da escrita, de um modo semelhante ao que tinha feito em 1969: "Y de cómo la escritura, esa 'máquina de engaños', puede tender sobre el abismo su irrefutable y a la vez incierto puente de signos, para oponerse a tanta precariedad, a tanta incertidumbre, y, también, a la muerte" (1984, p. 36).

${ }^{8}$ SARLO, 1993, pp. 29-30.

${ }^{9}$ GAMBAROTTA, 2006, pp. 238-9.

${ }^{10}$ Certamente a de Hendrix não é uma história de fracassos. É, 
de Desiderio, deve entender-se em relação a suas performances frequentemente escandalosas no palco, mas, além disso, supõe a decisão explícita de trazer para um universo de referências literárias, de alta literatura - com o qual estaríamos num terreno saeriano -, uma referência proveniente do rock. ${ }^{11}$

sem dúvida, o guitarrista mais inovador de sua época e talvez de toda a história do rock. A trajetória de Hendrix em 1967 é de uma vertiginosa ascensão. No fim do ano anterior - outubro - forma seu grupo The Jimi Hendrix Experience, com que estréia em Evreux, França. Baseando-se no trêmulo, algo completamente esquecido pelos guitarristas posteriores a Hank Marvin, Hendrix dá forma e dimensão a cada configuração de feedback, de distorções sonoras e de sons puramente eletrônicos, chegando a subir os cursores do amplificador muito acima do nível máximo que os fabricantes tinham previsto. Toca a guitarra colocando-a nas costas, entre as pernas, usando os dentes, friccionando-a contra a caixa dos amplificadores, contra o longo pé do microfone e muitas vezes, quando está cansado desses jogos, termina quebrando o instrumento em mil pedaços, colocando fogo... ou ambas as coisas. Em 31 de março o grupo inicia uma turnê de 25 dias pela Grã Bretanha. Tratava-se de concertos "package", já que o programa de cada apresentação previa a atuação de Walker Brothers, Engelbert Humperdinck e Cat Stevens; finalizava The Jimi Hendrix Experience. Um elenco de talentos realmente incoerente. Entretanto, a segunda canção, 'Purple haze', divulgada pela companhia discográfica de Kit Lambert, Track Records, entra rapidamente nas listas de sucesso; Jimi Hendrix aparece na primeira página de todos os periódicos quando, no fim do primeiro concerto, põe fogo na guitarra. O espetáculo é qualificado como obsceno e socialmente perigoso, por isso Hendrix é advertido repetidas vezes a moderar os tons mais agressivos. Com o fim da turnê, Hendrix se converte num personagem de grande popularidade.

${ }^{11}$ Fabián Casas faz algo similar no conto "Casa con diez pinos" (escrito aproximadamente em 2001), onde o personagem parodiado é Juan José Saer. $\mathrm{O}$ título do conto remete a uma canção do grupo de rock argentino Manal e diz o seguinte:“El Gran Escritor se quedó 
Mas Desiderio não é qualquer poeta e La zanjita não é qualquer livro. Frequentemente tem se assinalado que La zanjita, publicado em 1992, é um livro central para a nova poesia dos anos noventa. $O$ tratamento da linguagem oral, que esquiva o meramente coloquial, sua topografia bairrista que remete à margem, à pobreza e ao jovem proletariado, constituem o pontapé inicial de uma poesia argentina ${ }^{12}$ que encontrava outras iconografias e escutava outras linguagens que deram conta de uma experiência individual e social radicalmente diferente, tramada pela demolição do alfonsinismo, a ascensão do menemismo e um mundo que no lapso de dez anos parecia ter mudado mais que nos últimos duzentos.

O segundo texto citado de Gramuglio propunha a "zona" como uma categoria conceitual e espacial para pensar a literatura de Saer, que de modo espiralado, como a de Balzac, retomava personagens, desenvolvia situações e ia construindo uma topografia litorânea. Se isso foi pensado com Saer, me pergunto, por que não pensar a "valetinha" como a zona de onde esses jovens poetas começam a publicar a partir dos anos noventa? É a partir da "valetinha", assim "pequenina" porque a outra seria "a grande literatura", que se deve compreender a

rumiando algo. Entonces, como si fuera un médium en trance, me empezó a dictar el super canon: Borges, Macedonio, Juan L. Ortiz, Faulkner, Onetti, Musil, Joyce, Kafka. Me parecía estar en la cancha escuchando a La voz del Estadio pasar la formación de un equipo de muertos. Cuando el listado pareció llegar a su fin, yo, tímidamente, le pregunté si le gustaba Ricardo Zelarayán. “¿Zelarayán?” me dijo. “¿Es un escritor argentino?”. Le dije que sí. Se quedó pensativo un rato largo, mirando la mesa, la tacita blanca de café. Era Anatoli Karpov pensando qué pieza mover. Después agachó el mentón, se durmió, roncó, pedorreó". CASAS, Los lemmings, 2005, p. 45.

${ }^{12}$ Aos nomes de Desiderio, Rubio e Gambarotta podem se somar os Daniel Durand, Laura Wittner, Carlos Batilana, Fabián Casas. 
aposta pelo fracasso de Gambarotta, pois a partir dali e ali não só há um dicionário restrito, mas também, como aponta Edgard Dobry, "um discurso da desilusão, deliberadamente manchado de barro e graxa, quando não de sangue, com um quê de asco e mofo, com uma absoluta falta de ilusões". ${ }^{13} \mathrm{~A}$ "valetinha" como topos chama atenção para a necessidade de que o político - e o desencanto que foi inerente aos anos noventa - adquira outro regime de visibilidade e outros enunciados, menos afins ao luxo lexical que poderia expressar a prosa de Saer, e mais propenso a escutar os novos murmúrios "lúmpenes" e os restos de um passado que parecia extinguido. A "valetinha" é um topos, uma localização de onde se obtém outra visão, porque como se diz em Punctum: "Enfocando una linterna desde el margen izquierdo / se obtienen sombras transversales en la escenografía"14.

\section{Ver e ouvir a partir da valeta}

Composto por trinta e nove partes, Punctum é um poemário protagonizado por uma série de personagens, Guasuncho, Cadáver, Gamboa e Confuncio, que perambulam pelas margens de Buenos Aires, nas cidades da região metropolitana da grande Buenos Aires como Gerli ou Hurlingham, ou em pequenas cidades provincianas como Concórdia; escutam punk, heavy metal, trash; se declaram futebolistas. Nas televisões desproporcionadas assistem velhas séries como Bonanza ou Kojac; dormem sobre colchões, deitados no chão. Parecem afásicos, com problemas para nomear ou lembrar, ou ainda ler. Não esperam nada, não compreendem muito, quando podem, se prendem aos objetos que os rodeiam; um garfo, uma laranja, um balde com água parada.

${ }^{13}$ DOBRY, 2006, p. 132-3.

${ }^{14}$ GAMBAROTTA, 2011, p. 90. 
Em Punctum, somam-se dois períodos históricos concretos da história da Argentina; os anos setenta, através de uma série de referências às organizações armadas e às organizações sindicais peronistas; e os anos noventa que, sem ser mencionados de modo explícito, resultam nas imagens desoladas, nas paisagens miseráveis, na trama de uma indústria devastada. Emergem em seus efeitos, em alguns nomes, sem que haja uma referência concreta. Mas Punctum, longe de nos oferecer imagens reconhecíveis, é uma operação sobre a língua que se apresenta como desmontagem, e uma sucessão de enjambements que quebram o sentido ou apresentam o sentido e a história - a dos anos setenta, a dos anos noventa - como ruína.

Vou me deter em primeiro lugar na operação de desmontagem e descrever alguns de seus efeitos. Muitos dos versos que compõem Punctum nos induzem a pensar que estamos diante de um verso depurado, onde um objeto emerge com nitidez. Dou alguns exemplos "heladeras en desuso / dejadas al fondo del baldío, unos hombres / colocando balizas / que van a titilar de noche alrededor de un pozo"; ${ }^{15}$ ou "Vienen amigos noctámbulos con camperas, / tienen escudos de STP bordados en las mangas, / apagan cigarrillos en las plantas". ${ }^{16}$ Parece que estamos diante de uma escrita apegada ao objeto, sem metáforas (e nesse sentido, é o modo pelo qual Gambarotta enuncia o fracasso da literatura). A nitidez produzida pela desmontagem, contudo, não se deve entender como transparência ou simplicidade. A fragmentação é, como afirma Ana Porrúa, a textura de Punctum. As imagens de Gambarotta não são unicamente geladeiras, terrenos baldios e faróis "são operações que enlaçam e desenlaçam o visível e sua significação [...] que produzem e desviam as expectativas", ${ }^{17}$ porque emergem no marco de uma narração cuja assinatura é o corte.

\footnotetext{
${ }^{15}$ GAMBAROTTA, 2011, p. 37.

${ }^{16}$ GAMBAROTTA, 2011, p. 55.

${ }^{17}$ RANCIÈRE, 2011, p. 26.
} 
Por outro lado, a operação de desmontagem possui um suplemento que contribui com o desconcerto que parece atravessar todo o livro. Resultado de uma afasia que invade os personagens, os objetos perdem seu nome: "Cómo se llama eso que cuelga de la pared, / cómo se llama eso que cubre la lámpara / Rodeado de cosas sin nombre...", ${ }^{18} \mathrm{em}$ um desses tantos momentos de perda. E junto com a afasia - uma forma do ouvido - "o" ou "os personagens" também padecem de um tipo de dislexia visual "No lee, Confuncio, / en el tablero que anuncia / la partida de los servicios / Diamante sino Diamante, / no Bahía Blanca sino Bahía Blanca. / Tiene problemas para entender / los números que informan / el horario de salida de los micros". ${ }^{19}$

Nos versos de Punctum a língua aparece de duas maneiras: com uma naturalidade que na verdade deve ser lida como radical desnaturalização, e como uma língua impotente para capturar a matéria do mundo - outro fracasso da literatura. Os personagens de Punctum, que costumam se apresentar em estado de sonolência ${ }^{20}$, não controlam a língua que os habita, que os confunde, que os faz sumir na penumbra ${ }^{21}$. Este caos produzido pela desmontagem, a afasia e a dislexia, é, por

${ }^{18}$ GAMBAROTTA, 2011, p. 10.

${ }^{19}$ GAMBAROTTA, 2011, p. 39-40.

${ }^{20}$ Assim começa: “Una pieza / donde el espacio del techo es igual / al del piso que a su vez es igual / al de cada una de las cuatro paredes / que delimitan un lugar sobre la calle. / La bruma se traslada a su mente / vacía, no sabe quién es...." (GAMBAROTTA, 2011, p.9).

${ }^{21}$ As referências ao óxido são abundantes no livro. Dou três exemplos: "Las manchas de óxido en el cielo- / el color de la luz sobre las cosas, el cielo que se retrae y es óxido borroneado / entre sus ojos y cae dormido de nuevo, pero aparece / un orden en la materia despierta."(GAMBAROTTA, 2011, p.9); "En el sentido estricto,/ ninguna, a no ser / nada, separa esa noche / de las manchas de óxido / que se despliegan hoy"; "si lo que seguía al trueno era relámpago, / o, a decir verdad, viceversa; lo que parecía / ser, lo que sin lugar 
um lado, a forma na qual se abre um passo para a memória uma forma da escuta pelo ouvido ou o ouvido chocado pela memória, ou simplesmente uma escuta descontrolada e afásica - "el nombre innombrable que toman los hechos / pasados haciendo eco en el presente", 22 e que induz ao sonho em plena vigília porque tudo parece ter sido pacificado

pacificados, los músculos de la cara:

pacificados. Las fundiciones de acero: pacificadas; los Altos Hornos Zapla:

pacificados; en paz descansan las perforadoras. ${ }^{23}$

Por outro lado, esse caos é o presente de uma língua guardada pelas desventuras de uma democracia traída. Observemos um exemplo nesse segundo sentido. Na primeira parte de Punctum se diz "mira la foto de una amiga / que estuvo internada / en un hospicio de París. Eso / suena pretencioso y, releyendo, / sería mejor cambiar París por Federación, hospicio / por hospital, internada por encerrada...". ${ }^{24}$ A substituição aqui, pode-se pensar, funciona a serviço da desmontagem, mas de uma desmontagem literária se se quer: substitui-se essa cidade literária - Paris, pátria de Saer - por uma pequena cidade da província de Entre Rios - Federación -, substitui-se a palavra "hospício" pela mais coloquial "hospital". Entretanto, Paris por Federación e hospício por hospital não são simples substituições lexicais, são substituições às vezes literárias e sociais, que remetem a uma margem social: não se vai a Paris, vai-se a Federación ou também a Bahía Blanca ou ao Bairro Pepsi ou a Cidade Evita; não se interna alguém no hospício,

a duda era, lo que empezó / siendo una mancha de óxido en el cielo" (GAMBAROTTA, 2011, p. 66).

${ }^{22}$ GAMBAROTTA, 2011, p. 39.

${ }^{23}$ GAMBAROTTA, 2011, p.49.

${ }^{24}$ GAMBAROTTA, 2011, p.15. 
interna-se num hospital, seguramente público, seguramente desmantelado.

Em segundo lugar, e como apontei anteriormente, em Punctum, há uma política do corte, com enjambements brutais, e a presença enfática de pontos suspensos e linhas entre os versos. Nesse marco, não só se deve falar de uma política do corte, mas da história política como corte. Quero dizer, não se trata de repor aquilo que está omitido, seja em relação à história política, seja em relação ao presente, pois o fragmento não tem uma função alegórica, é significativo em si mesmo, resto encriptado de uma fala morta. Vou me deter em uma série de versos para exemplificar o que acabo de dizer:

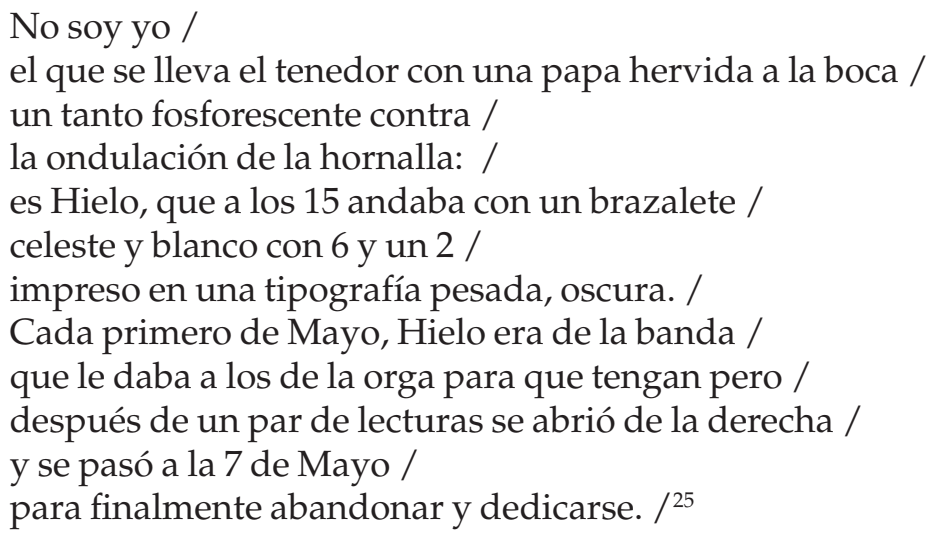

Como se pode notar, a série de versos está toda encavalgada, mas o último verso, que esperamos que se encavalgue no verso seguinte, encerra-se com um ponto. Esse verso, como oração isolada, é gramaticalmente incorreto porque o verbo "dedicar-se" requer um complemento. Isso significa que o ponto corta o sentido. Assim mesmo, nos versos citados há informações que remetem à história política da Argentina,

${ }^{25}$ GAMBAROTTA, 2011, p.45. 
o "un 6 y un 2", alude às 62 organizações peronistas, "la orga" alude à organização armada Montoneros, "o 7 de Maio" é um agrupamento de esquerda. Sabemos, pelo menos os argentinos de certa idade sabem, que os versos falam do peronismo, das diferentes tendências peronistas que tiveram uma forte presença durante os anos setenta; sabemos que essas siglas correspondem à direita e à esquerda peronista. Mas a quê tudo isso alude nos versos? O que significa? Ali há um sentido que necessita ser decifrado? Se o sentido nos é negado a ponto de imobilizar o verbo "dedicar-se", por que aparecem essas referências? As referências estão partidas, pois não é 62, mas sim 6 e 2; não são montoneros, mas a "orga", não são a agrupação 7 de Maio, mas "o 7 de Maio" 26, mais que citações ou alusões, são, efetivamente, fragmentos, e o passado que trazem consigo advém exausto, quebrado, arruinado.

\section{O show dos mortos}

O título do livro, Punctum, que remete à categoria que Roland Barthes postula para as imagens fotográficas em seu livro La câmara lúcida, pode dar maior clareza ao expressado nos parágrafos anteriores. A definição do punctum de Barthes diz o seguinte: "é esse acaso que vai além de mim (mas também me machuca, me fere)"27. Com efeito, há na imagem algo irredutível que a subjetividade não é capaz de decodificar, que na verdade a põe em crise. Junto ao punctum, que nem toda fotografia contém, Barthes propõe o studium: "por meio do studium me interesso

\footnotetext{
${ }^{26}$ Em poucos versos mais abaixo, no poema não será a UOM (que significa União Obreira Metalúrgica, que remete a Rucci e ao Perón da Praça do $1^{\circ}$ de Maio), mas, a U / O / M, que se rompe em uma letra para cada verso.

${ }^{27}$ BARTHES, 2009, p. 65.
} 
por muitas fotografias, seja porque encaro-as como testemunhos políticos, seja porque saboreio-as como quadros históricos" 28 . O studium, pelo contrário, funciona como informação, como relato histórico, como aquilo que é transmissível. Com o studium aprendo, com o punctum desaprendo.

Algumas questões que na verdade são uma digressão antes de chegar ao ponto (ou ao punctum). É interessante destacar, como se depreende da citação anterior, que Barthes coloca o "testemunho político" ao lado do studium, e até é capaz de afirmar o seguinte:

Folheava uma revista ilustrada. Detive-me em uma foto. Nada extraordinário: a trivialidade (fotográfica) de uma revolta na Nicarágua; uma rua em ruínas, dois soldados com capacete patrulhavam; em segundo plano passam dois monges. "Eu gostava da foto?", "O que me interessava?", "O que me intrigava?" Não era apenas isso. Simplesmente existia (para mim). ${ }^{29}$

Não se pretende dizer aqui que Barthes se interessa por uma revolta na Nicarágua, mas sim se adverte que o studium o deixa indiferente, que ocupa um lugar subalterno em sua valorização, que o que realmente lhe interessa detectar, em cada imagem, é o punctum, e que divide, claro, punctum e política.

Então como pensar o título do livro de Gambarotta, que não deixa de lado a recente história política da Argentina, mas que nos direciona de imediato à categoria que Barthes propôs, sim, o próprio Barthes coloca a política - a revolução na Nicarágua é um exemplo ainda que haja outros - do lado do studium. Na verdade, creio que o punctum de Gambarotta se aproxima da releitura que, via Lacan $^{30}$, realiza Hal Foster em El retorno

${ }^{28}$ BARTHES, 2009, p. 64

${ }^{29}$ BARTHES, 2009, p. 53-54.

${ }^{30} \mathrm{Na}$ verdade, Barthes também desenvolve esta categoria a partir de 
de lo real, e por meio do qual propõe a categoria de "realismo traumático" para pensar a produção - um momento dela - de um artista como Andy Warhol. Se Gambarotta reconfigura essa categoria, se adota, em definitivo, do político ao real, não por Barthes deve ser deslocado ao quarto dos trapos velhos. A tríade que propõe no afastado quarto de $A$ Câmara Clara é um bom complemento para pensar a ideia de retorno traumático, que é o que em definitivo propõe Hal Foster, e é a matéria que compõe Punctum - matéria que permite o cruzamento entre a história e a poesia. Ali, Barthes propõe uma divisão entre o Operator, o Spectator e o Spectrum, e afirma sobre essa última categoria, que é a que me interessa: "esta palavra mantém através de sua raiz uma relação com 'espetáculo' e acrescenta-lhe algo terrível que há em toda fotografia: o retorno do morto". ${ }^{31}$

O Punctum de Gambarotta nos fala do retorno de um sussurro traumático, o sussurro de uma história que resiste a ser "enterrada", um sussurro que como pulsão insiste e inscreve os setenta nos noventa mediante estilos e fragmentos. Retorno do morto, ou para estar em sintonia com o poemário, retorno de um regime do cadáver que congrega tanto os mortos políticos, que insistem em regressar, ou que são convocados,

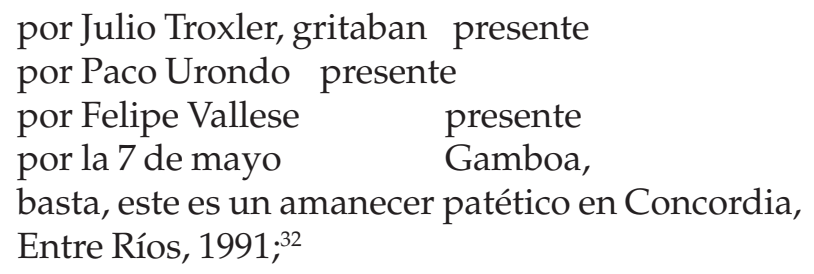

Lacan, da mesma forma que em O Prazer do Texto.

${ }^{31}$ BARTHES, 2009, p.39.

${ }^{32}$ GAMBAROTTA, 2011, p.82. 
Como aqueles que perambulam pelo poema em um ir e vir que sempre fica pela metade do caminho: "Recién cuando Kwanfu-tzu anda / bordeando el río se encuentra a Confuncio, que se quedó / sin cigarrillos antes de entrar / a la terminal y las dos partes se vuelven a juntar / y son de nuevo Confuncio, indivisible, que no puede / decidir, iluminado por el único foco del micro, / cuál de los dos tomar:" ${ }^{\prime \prime 3}$. São esses retornos, ruinosos, mas também ruins para uma democracia que pretende esquecer, fragmentos, em suma, traumáticos, os que convertem o Punctum num texto falado por esse passado militante dos setenta, que, contudo não consegue dotar-se de sentido, e por um presente em penumbras, coberto pelo óxido e o lixo de uma sociedade pós-industrial.

${ }^{33}$ GAMBAROTTA, 2011, p.39. 


\section{Referências bibliográficas}

BARTHES, Roland. El placer del texto. Buenos Aires: Siglo XXI, 2007. . La cámara lúcida. Buenos Aires: Paidos, 2009.

CASAS, Fabián. Los lemmings. Buenos Aires: Santiago Arcos editor, 2005. DESIDERIO, Juan. La zanjita. Buenos Aires: Ediciones Deldiego, 2001. DOBRY, Edgardo. "Poesía argentina actual: del neo-barroco al objetivismo. (y más allá)", site da revista "Punto de Vista" (www. bazaramericano.com)

FONDEBRIDER, Jorge (comp.). Tres décadas de poesía argentina. Buenos Aires: Eudeba, 2006.

FOSTER, Hal. El retorno de lo real. Madrid: Akal, 2001.

GAMBAROTTA, Martín. "El habla como materia prima", In: FONDEBRIDER, Jorge (comp.). Tres décadas de poesía argentina. Buenos Aires: Eudeba, 2006.

. Punctum. Buenos Aires: Mansalva, 2011.

GRAMUGLIO, María Teresa. "Las aventuras del orden”. In: Los libros n³, Buenos Aires, septiembre 1969.

. "Juan José Saer: el arte de narrar". In: Punto de Vista no 6, Buenos Aires, mayo 1977.

. "La filosofía en el relato. Sobre 'El entenado' de Juan José Saer". In: Punto de Vista n 20, Buenos Aires, mayo 1984.

PRIETO, Martin. Breve historia de la literatura argentina. Buenos Aires: Taurus, 2006.

RANCIÈRE, Jacques. El destino de las imágenes. Buenos Aires: Manantial, 2011.

SAER, Juan José. Glosa. Buenos Aires: Seix Barral, 1995.

SARLO, Beatriz. "La condición mortal". In: Punto de Vista n ${ }^{\circ} 46$, Buenos Aires, agosto 1993. 


\section{Resumo}

$\mathrm{O}$ artigo propõe-se a analisar, segundo um enfoque comparatista, a poesia de Martin Gambarota, jovem poeta argentino.

\section{Resumé:}

This paper examines, from a comparative approach, the poetry of Martín Gambarotta, a young argentine poet. 